\title{
EVALUATION OF LIGHT SUPPLY IN THE PUBLIC UNDERGROUND SAFE SPACES BY USING OF COPRAS-SWARA METHODS
}

\author{
Jalal NAKHAEI a, Shahin LALE AREFI b, Mahdi BITARAFAN c, Simona KILDIENE d,* \\ ${ }^{a}$ Department of Art and Architecture Engineering, Islamic Azad University, Central Tehran Branch, \\ Iran \\ ${ }^{b}$ Department of Civil Engineering, University of Mohaghegh Ardabili, P.O. Box 56199-11397, Ardabil, \\ Iran \\ c Department of Civil Engineering, Engineering Research Institution of Natural Disaster Shakhes \\ Pajouh, P.O. Box 81655-1537, Isfahan, Iran \\ ${ }^{d}$ Research Institute of Smart Building Technologies, Vilnius Gediminas Technical University, \\ Sauletekio al. 11, LT-10223 Vilnius, Lithuania
}

Received 18 February 2015; accepted 4 October 2015

\begin{abstract}
One of the most significant issues in the safe underground spaces is the supply of light during the conditions in which there is no possibility to use national electricity network in crisis. Hence, attention to the source management of light supply possesses worthy importance. Light is one of the important issues in underground safe spaces which must be noticed with particular obligations. In the research, in order to evaluate variety of light supply methods in underground safe spaces, a questionnaire was set in order to weigh affective indexes up and score each method. To determine the best index among different indexes, SWARA method was applied; then COPRAS method was used in order to analyze data of the questionnaire that the best choice among various strategies could be chosen. Results represented that the choice of light supply by the lamp with battery source to provide light for city shelters is the best. According to results gotten from this method, choices of light supply by the fossil fuel light, light supply by the urban power source lamp, light supply by the mirror and light supply by fiber optics have been ranked in second, third, fourth and fifth positions, respectively.
\end{abstract}

KEYWORDS: Safe space; Light supply; Management; SWARA; COPRAS

\section{INTRODUCTION}

Considering developments of weapons and importance of vital and strategic functions such as data centers, communication centers, significant industrial centers, control and command centers, special shelters, and etc. to create security and national defense during the war, making underground safe spaces for these functions is an inevitable affair. In designing of safe spaces, a threat is usually assigned as the cause threat and their loading are done on the basis of this threat. Through the growth of penetration and degradation power of enemy's weapons, present structures cannot possess sufficient resistance against these weapons (Lale Arefi, Bitrafan 2013). The designer must consider all elements of the emergency environment when designing the space. Provisions must be made for emergency egress, light and ventila-

* Corresponding author. E-mail: simona.kildiene@vgtu.lt tion (without electric power), blast closures, water, sanitation, and food. The option of upgrading the space in a crisis should be considered.

Combination of form, type and the technique of arrangement or juxtaposition of different volumes and spaces is one of the important topics in underground spaces, too and has been considered by Bitarafan et al. (2013).

Even though spaces underground is not something new. In different countries, cultures and periods, it has had different meanings and has been utilized according to the needs of the era. It has served as a shelter, storage place and a graveyard. An underground space is observable in different forms such as in usual underground, earthy hills with specific thickness of soil on their tops, and the structures completely inside the ground (Vaezizadeh, Kazemzade 2013). An underground storm-type 
shelter could protect your family from weather related threats including tornadoes and hurricanes. A well-stocked basement with emergency lighting and heat could provide comfort during an extended power outage or snowstorm. A fireproof type shelter could provide life saving protection for family members in the event of a fast moving forest fire or home fire. A bulletproof type shelter hidden in a bedroom closet can save the lives of family members during breakins by lawless vandals. Some of the drawbacks and negative associations with the underground that are mentioned in Carmody and Sterling (1993) are: darkness combined with humid air; underground is also related to death and burial; fear of entrapment from structural collapse; disorientation; loss of connection with the natural world; lack of natural light and poor ventilation (Durmisevic 1999).

Today's technology has been able to cope with and overcome many of the above mentioned aspects, and expectations are that in the future it will deal with such problems even more effectively and efficiently. Light is the understanding key of the space that affects directly on the grasp quality of the space. Light can enter underground spaces from different ways, it can be supplied from ceiling light, an inner yard or atrium, and/or from one or more sides of the building. During the centuries, philosophers and scientists have construed light as a material and spiritual entity and studied and considered its major source in the sun. Natural light which is the source of the universe, forms objects whereas strikes the surfaces of them and gives them depth through accumulating the shade in their backs. Light which is comprehension key of the space, impacts directly upon the space quality and architecture through this light is appeared (Ziabakhsh, Mokhtabad-Amrei 2010).

Light is the first condition for any kind of vision comprehension. In darkness, we can see neither the space nor the form and color. Not only is light a physical essential, also a psychological value which is one of the important factors of man's life in all fields. Light is the most diaphanous, softest, easiest and cheapest existed structural substance in the production of qualities and objects needed for human's environment. It's something that provides possibility of personification and giving life to the daily activities and releasing the life in the variable imaginations and mental states. Light welcomes us like a comfortable sofa in a tough and prosaic space. Hence, light is the most suitable structural substance which can give our routines form, beauty, enjoyment and comfort (Kashi 2009). The light is the most significant inner element of environment after food that has a controlling role on the body. In fact, psychological influence of light depends on a completed light spectrum which strikes the eyes and this light spectrum effects on the duty and trend of nerve transmitters. Now, designing the light of buildings is based on scientific rules in addition to experimental method. Satisfactory light helps man's peace and raises work efficiency, as well. Moreover, due to reduction of accidents caused by insufficient light, it helps with safety of the environment, much. Satisfactory light means that not only must sufficient light be provided in the environment; also light quality must be in a manner that inflicts minimum pressure on the eyes.

Building regulations have considered light supply model such as emergency light for multipurpose shelters (which are not used just as shelters) and Emergency light supply has been recommended (FEMA 361 2000). In the essay, considering the importance of underground safe spaces particularly in mega cities, procedure of light supply has been evaluated, besides this point that failure possibility of infrastructures like electricity is too much in the crisis conditions. Now a day, since underground spaces are lighted only by specific lamps, electromagnetic lamp and etc., it's necessary to take strategies in order to transmit light from earth surface to its depth to make the continuity of essential services possible.

The recent developments about role of light in architectural space are listed below:

- Shin et al. (2011) wrote about daylighting of a light pipe used in underground parking lots.

- Vaezizadeh and Kazemzade (2013) describe different strategies for light provision in vernacular underground architecture.

- Xiaobin et al. (2014) explore lighting environment in underground architecture.

- Alcini et al. (2015) wrote about simulation of day-lighting conditions in a virtual underground city.

Therefore, the major issue of the research is determination and assessment of variety of the methods of light transmission or light supply in underground safe spaces during the national power failure.

\section{RECOGNITION METHOD OF IMPLE- MENTING THE MODEL OF ASSESSMENT AND ANALYSIS OF RESULTS}

In this study in order to assess methods of light supply in underground safe spaces, first kinds of these techniques were determined through library 
references; then all pivots on the agenda for assessment of light supply techniques for underground safe spaces in the crisis were exploited through interview with experts in this field; and to survey experts, 16 people of them who had acquaintance with architecture, construction management, tunnel engineering and crisis management were exposed to a questionnaire in order to weigh up affective indexes and score each method (according to Table 1), as well.

Table 1. Statistics of experts' community

\begin{tabular}{lll}
\hline Expertise & Education degree & Number of experts \\
\hline 1) Architecture & Ph.D & 2 \\
& M.Sc & 1 \\
2) Construction & Ph.D & 2 \\
management & M.Sc & 0 \\
3) Tunnel & Ph.D & 3 \\
engineering & M.Sc & 2 \\
4) Crisis & Ph.D & 4 \\
management & M.Sc & 2 \\
\hline
\end{tabular}

In the following, SWARA and COPRAS methods were applied in order to analyze criteria and results of statistical community's questionnaires.

\subsection{Step-wise weight assessment ratio analysis (SWARA) method}

Weight assessment is an important issue in many MADM problems. Some famous weight assessment approaches in the literature include analytic hierarchy process (AHP) (Saaty 1980), analytic network process (ANP) (Saaty, Vargas 2001), Entropy (Shannon 1948; Sušinskas et al. 2011; Keršulienè, Turskis 2011), FARE (Ginevičius 2011), SWARA (Keršulienè et al. 2010), etc. Among these methods, SWARA method is one of the brand-new ones.

In this method, the expert has an important role on evaluating and calculating weights. Also, each expert has chosen the importance of each criterion.
Next, each expert ranks all the criteria from the first to the last one. An expert uses his or her own implicit knowledge, information and experiences. Based on this method, the most significant criterion is given rank 1 , and the least significant criterion is given last rank. The overall ranks of the group of experts are determined according to the mediocre value of ranks (Keršuliene, Turskis 2011).

The ability to estimate experts' opinion about importance ratio the criteria in the process of their weights determination is the main element of this method (Keršulienè et al. 2010). Moreover, this method is helpful for coordinating and gathering data from experts. Furthermore, SWARA method is uncomplicated and experts can easily work together. The main advantage of this method in decision making is that in some problems, priorities are defined based on policies of companies or countries and there aren't any needs for evaluation to rank criteria.

In other methods like AHP or ANP, our model is created based on criteria and experts' evaluations will effect on priorities and ranks. Therefore, SWARA can be useful for some issues that priorities are known former according to situations and finally, SWARA proposed for applying in certain environment of decision making. All the developments of decision making models based on SWARA method up to now are listed in Table 2.

The process of determining the relative weights of criteria using SWARA method can accurately be shown by using the following steps (Stanujkic et al. 2015):

Step 1. The criteria are sorted in descending order based on their expected significances.

Step 2. Starting from the second criterion, the respondent expresses the relative importance of criterion $j$ in relation to the previous $(j-1)$ criterion, for each particular criterion. According to Keršulienè et al. (2010), this ratio is called the Comparative importance of average value, $s_{j}$.

Table 2. Developments of decision making models based on SWARA method

\begin{tabular}{|c|c|}
\hline Authors/Publication date & The scope of application \\
\hline Hashemkhani Zolfani et al. (2015) & Multiple Nash equilibriums and evaluation of strategies \\
\hline Vafaeipour et al. (2014) & Assessment of regions priority for implementation of solar projects in Iran \\
\hline $\begin{array}{l}\text { Hashemkhani Zolfani and Zavads- } \\
\text { kas (2013) }\end{array}$ & Sustainable development of rural areas' building structures based on local climate \\
\hline Hashemkhani Zolfani et al. (2013a) & Design of products \\
\hline Hashemkhani Zolfani et al. (2013b) & $\begin{array}{l}\text { Selecting the optimal alternative of mechanical longitudinal ventilation of tunnel } \\
\text { pollutants }\end{array}$ \\
\hline Hashemkhani Zolfani et al. (2013c) & Investigating on the success factors of online games based on explorer \\
\hline Hashemkhani et al. (2013d) & Decision making on business issues with foresight perspective \\
\hline Aghdaie et al. (2013a) & Machine tool selection \\
\hline
\end{tabular}


Step 3. Determine the coefficient $k_{j}$ as follows: $k_{j}=\left\{\begin{array}{cc}1 & j=1 \\ s_{j}+1 & j>1\end{array}\right.$.

Step 4. Determine the recalculated weight $q_{j}$ as follows:

$$
q_{j}=\left\{\begin{array}{cc}
1 & j=1 \\
\frac{k_{j-1}}{k_{j}} & j>1
\end{array} .\right.
$$

Step 5. The relative weights of the evaluation criteria are determined as follows:

$$
w_{j}=\frac{q_{j}}{\sum_{k=1}^{n} q_{k}},
$$

where: $w_{j}$ denotes the relative weight of criterion $j$.

\subsection{COPRAS (complex proportional assessment) method}

In order to evaluate the overall efficiency of an alternative, it is essential to identify most important criteria, to evaluate alternatives and assess information with respect to these criteria; develop methods for evaluating the criteria to meet the DMs' needs. Decision analysis is concerned with the situation in which a DM has to choose among several alternatives by considering a particular set of, usually conflicting criteria. For this reason, Complex proportional assessment (COPRAS) method which was developed by Zavadskas and Kaklauskas (1996) can be applied. In real situations, the most of the criterion for evaluating alternatives deals with vague feature, and values of criteria cannot be expressed with exact numbers.

The recent developments of decision making models based on COPRAS method are listed in the Table 3.
The procedure of applying the COPRAS method consists in the following steps:

1. Selecting the set of the most important criteria, describing the alternatives.

2. Constructing the decision-making matrix $X$ :

$$
X=\left[\begin{array}{cccc}
x_{11} & x_{12} & \ldots & x_{1 m} \\
x_{21} & x_{22} & \ldots & x_{2 m} \\
\vdots & \vdots & \ddots & \vdots \\
x_{n 1} & x_{n 2} & \ldots & x_{n m}
\end{array}\right] ; i=\overline{1, n} \text { and } j=\overline{1, m}
$$

where: attribute $j$ is in the alternative $i$ of a solution; $m$ is the number of attributes; $n$ is the number of the alternatives compared.

3. Determining significances of the criteria $q_{i}$.

4. Normalizing the decision-making matrix $\bar{X}$. The normalized values of this matrix are calculated as:

$$
\bar{x}_{i j}=\frac{x_{i j}}{\sum_{j=1}^{n} x_{i j}} ; i=\overline{1, n} \text { and } j=\overline{1, m}
$$

After this step we have normalized decision making matrix:

$$
\bar{X}=\left[\begin{array}{cccc}
\bar{x}_{11} & \bar{x}_{12} & \ldots & \bar{x}_{1 m} \\
\bar{x}_{12} & \bar{x}_{12} & \ldots & \bar{x}_{2 m} \\
\ldots & \ldots & \ddots & \ldots \\
\bar{x}_{n 1} & \bar{x}_{n 1} & \ldots & \bar{x}_{n m}
\end{array}\right]
$$

5. Calculating the weighted normalized decision matrix $\hat{X}$. The weighted normalized values

\begin{tabular}{|c|c|}
\hline Authors/Publication date & The scope of application \\
\hline Pitchipoo et al. (2014) & Optimize blind spot in heavy vehicles by COPRAS decision modeling \\
\hline Ghorabaee et al. (2014) & $\begin{array}{l}\text { Multiple criteria group decision-making for supplier selection based on COPRAS } \\
\text { method with interval type- } 2 \text { fuzzy sets }\end{array}$ \\
\hline Aghdaie et al. (2013b) & Market segment evaluation and selection \\
\hline $\begin{array}{l}\text { Hashemkhani Zolfani et al. } \\
\text { (2012a) }\end{array}$ & Supplier selection \\
\hline $\begin{array}{l}\text { Hashemkhani Zolfani et al. } \\
(2012 b)\end{array}$ & Quality control manager selection \\
\hline Aghdaie et al. (2012) & Prioritizing projects of municipality \\
\hline Bitarafan et al. (2012) & $\begin{array}{l}\text { Evaluating the construction methods of cold-formed steel structures in reconstruct- } \\
\text { ing the areas damaged in natural crisis }\end{array}$ \\
\hline Fouladgar et al. (2012) & Maintenance strategy selection \\
\hline Rezaeiniya et al. (2012) & Greenhouse locating \\
\hline
\end{tabular}
$\hat{X}_{i j}$ are calculated as follows:

$$
\hat{x}_{i j}=\bar{x}_{i j} \cdot q_{j} ; i=\overline{1, n} \text { and } j=\overline{1, m} \text {. }
$$

Table 3. Recent developments of decision making models based on COPRAS method 
where: $q_{i}$ is the significance of the $i$-th criterion. Then, the normalized decision-making matrix is:

$$
\hat{X}=\left[\begin{array}{cccc}
\hat{x}_{11} & \hat{x}_{11} & \ldots & \hat{x}_{11} \\
\hat{x} & \hat{x_{11}} & \ldots & \hat{x}_{11} \\
\vdots & \vdots & \ddots & \vdots \\
\hat{x}_{11} & \hat{x}_{11} & \ldots & \hat{x}_{11}
\end{array}\right] ; i=\overline{1, n} \text { and } j=\overline{1, m} .
$$

6. Calculating the sums $P_{i}$ of criterion values, whose larger values are more preferable:

$$
P_{i}=\sum_{j=1}^{k} \hat{x}_{i j} .
$$

7. Calculating the sums $R_{i}$ of criterion values, whose smaller values are more preferable:

$$
R_{i}=\sum_{j=k+1}^{m} \hat{x}_{j}
$$

In formula (10), $(m-k)$ is the number of criteria which must be minimized.

8. Determining the minimal value of $R_{i}$ as follows:

$$
R_{\min }=\min _{i} R_{i} ; i=\overline{1, n} .
$$

9. Calculating the relative significance of each alternative by $Q_{i}$ the expression:

$$
Q_{i}=P_{i}+\frac{R_{\min } \sum_{i=1}^{n} R_{i}}{R_{i} \sum_{i=1}^{n} \frac{R_{\min }}{R_{i}}}
$$

10. Determining the optimal criterion $K$ by the formula:

$$
K=\max _{i} Q_{i} ; i=\overline{1, n} .
$$

11. Determining the priority order of the alternatives.

12. Calculating the utility degree of each alternative by the formula:

$$
N_{j}=\frac{Q_{i}}{Q_{\max }} \times 100 \% .
$$

where: $Q_{i}$ and $Q_{\max }$ are the significances of the alternatives obtained from Eq (12).

\section{VARIETY OF LIGHT SUPPLY METHODS IN UNDERGROUNG SAFE SPACES}

There are different methods to supply light. In this section, these methods are explained, briefly and in respect of conditions and positions of mentioned location in addition to introduced indexes, any of these techniques can be employed. They are inclusive of:

- Mirror;

- Fiber optics;

- Lamp with city electricity source;

- Light with fossil fuel;

- Lamp with battery source.

\subsection{Light supply by the mirror (A1)}

Applying the mirror is one of the methods which can transmit light in the power failure times caused by damages of infrastructures. There are numerous samples of usage of this method for lighting such as the building of Reichstag in Berlin, location of the new German Parliament, in where natural light is reflected to the down building means the parliament through the hundreds of mirrors which make the middle funnel.

The building of Hong Kong Bank is another example in which light supply has become feasible due to light reflection from the surfaces of two huge mirrors. The sheet which collects sunlight in outside, contains hundreds of small mirrors which follow sunlight path and reflect it towards a concave mirror at the top of the atrium. This concave mirror directs light to the inside and even under the surface of the glass floor of the building.

Low economical expenditure of the implementation is one of its benefits. Defects of this method consist of destroying and damaging these kinds of systems, easily by enemy through making a blast load.

\subsection{Light supply by fiber optics (A2)}

In this technology, light enters fiber-optic from a light source which can be either artificial light (light of electric lamps) or natural light (sunlight) and through this; it's transmitted to the consumption place. Thus, light is transferred to any point that's not in the direction of its straight shining (Pezeshkpour, Motamedi 2005). Utility of this kind is that it is lacking of electricity of heat and dangerous ultraviolet radiations (pure and safe light) and moreover, due to this technology, daylight (free of heat and ultraviolet rays) can be transmitted to the inside of the space and the places unavailable to the sunlight (Narjabadi Fam et al. 2011). High efficiency and low electric consumption by comparison with other light instruments are other benefits of it. The most important fault of the method is its high expenditure. 


\subsection{Light supply by the lamp with city electricity source (A3)}

One of the useful methods to provide light for safe spaces is applying of the lamp with power source. One of its defects is that providing damages of infrastructures by explosion, the utilization of this method for supplying light encounters the difficulty and certainly, a replaced system, emergency power, must be available in order to provide light.

\subsection{Light supply by the light of fossil fuel (A4)}

Usage of fossil fuel sources is one of other methods of light supply in emergency conditions. Of the faults of this technique is the inadequacy of this energy source besides much environmental pollution. In damaging conditions of the power infrastructure, light can be produced by the systems which use fossil fuel like diesel generator for a few days in order to quit the crisis state; but the time of using this method is limited to few days and emergency conditions.

\subsection{Light supply by the lamp with battery source (A5)}

In this technique, various batteries can be applied to produce light. Batteries come in various kinds and are used according to the kind of their usages. These batteries are similar in component materials and different in structure and production process from each other. Types of available batteries which possess the most shares in the market include of vehicle batteries, specific batteries used in UPS systems named ups batteries and solar batteries, too. Batteries utilized in UPS for the reason of their usage in the limited times of emergency and power failure conditions, consist of fewer numbers of charge and recharge cycles rather than solar batteries; in addition, battery equipments of solar systems cost too much as opposed to UPS.

\section{DETERMINATION OF AFFECTIVE INDEXES ON THE CHOICE}

Affective indexes to choose methods of light supply for underground safe spaces were identified by the interview and survey of experts in this field; so that decision criteria are a set of economic and executive characteristics. In order to weigh up each index, SWARA method has been applied. Utilized criteria in the research are inclusive of:

1. Economic expenditure $\left(\mathrm{C}_{1}\right)$;

2. Reduction of mental effects $\left(\mathrm{C}_{2}\right)$;
3. Function and responding to the requirements $\left(\mathrm{C}_{3}\right)$;

4. Complication of execution $\left(\mathrm{C}_{4}\right)$;

5. Blast wave direction towards shelters $\left(\mathrm{C}_{5}\right)$.

\section{RESULTS}

\subsection{SWARA results}

In this section, SWARA is applied for evaluating the model of research presented in Table 1. Weights and relative importance of each criterion will be calculated in this section. Experts' ideas gathered and its results have been shown in Table 4 .

Table 4. Final results of SWARA method in weighting criteria

\begin{tabular}{|c|c|c|c|c|}
\hline $\begin{array}{l}\text { Cri- } \\
\text { te- } \\
\text { rion }\end{array}$ & $\begin{array}{l}\text { Compara- } \\
\text { tive impor- } \\
\text { tance of } \\
\text { average } \\
\text { value } s_{j}\end{array}$ & $\begin{array}{l}\text { Coefficient } \\
k_{j}=s_{j}+1\end{array}$ & $\begin{array}{l}\text { Recalculat- } \\
\text { ed weight } \\
w_{j}=\frac{x_{j-1}}{k_{j}}\end{array}$ & $\begin{array}{l}\text { Weight } \\
q_{j}=\frac{w_{j}}{\sum w_{j}}\end{array}$ \\
\hline C3 & & 1 & 1.0000 & 0.2488 \\
\hline $\mathrm{C} 1$ & 0.083 & 1.083 & 0.9234 & 0.2298 \\
\hline C5 & 0.083 & 1.083 & 0.8526 & 0.2121 \\
\hline $\mathrm{C} 4$ & 0.300 & 1.3 & 0.6558 & 0.1632 \\
\hline $\mathrm{C} 2$ & 0.117 & 1.117 & 0.5871 & 0.1461 \\
\hline
\end{tabular}

$s_{j}$ is calculated based on the average of expert's ideas.

The information was gained privately from each expert and the scale is based on multiples of five percent. The Importance of each criterion is calculated based on relative importance of higher criterion. Videlicet, 0.083 shows relative difference of $\mathrm{C} 3$ and $\mathrm{C} 1.0 .083$ is calculated according to experts' ideas and for illustrating $s_{j}$ all 11 ideas are presented here. Priority, weights and relative importance of each criterion is calculated with SWARA and economic factors are at the top of priority. Results of this step will be used in COPRAS method for evaluating alternatives.

As observed, the criterion of Function and Responding to the needs is placed in first rank that indicates the importance of this index versus other criteria. In this order, Economic cost and Complexity of implementation are in second and third positions. The lowest place belongs to Psychological effects that it shows its little importance by comparison with other indexes on the base of experts' opinions.

\subsection{COPRAS results}

After determining all weights of every criterion by SWARA method, COPRAS method was applied to 
evaluate and select four alternatives of high tech industries. At this stage of the application, the group of experts evaluated each alternative according to each criterion and Table 5 was developed.

Table 5. Initial decision-making matrix with values of the attributes describing the compared alternatives (COPRAS)

\begin{tabular}{llllll}
\hline & C1 & C2 & C3 & C4 & C5 \\
\hline Weights & 0.2298 & 0.1461 & 0.2488 & 0.1632 & 0.2121 \\
\hline opt & $\min$ & $\max$ & $\max$ & $\min$ & $\min$ \\
\hline A1 & 3.667 & 6.000 & 4.333 & 5.000 & 9.000 \\
A2 & 6.333 & 6.333 & 5.000 & 6.000 & 7.333 \\
A3 & 5.000 & 5.333 & 6.333 & 3.667 & 5.000 \\
A4 & 5.000 & 3.667 & 6.333 & 3.667 & 3.000 \\
A5 & 4.333 & 4.333 & 6.333 & 3.667 & 2.333 \\
$\Sigma$ & 24.333 & 25.667 & 28.333 & 22.000 & 26.667 \\
\hline
\end{tabular}

Besides, Table 5 indicates initial decision making matrix with the criteria values. For the weight of criteria, we used the weights in Table 5. As mentioned before, the aim of using SWARA is to determine important weights of criteria that will be employed in COPRAS method.

Table 6. Weighted normalized matrix

\begin{tabular}{llllll}
\hline & C1 & C2 & C3 & C4 & C5 \\
\hline opt & $\min$ & $\max$ & $\max$ & $\min$ & $\min$ \\
\hline A1 & 0.035 & 0.034 & 0.038 & 0.037 & 0.072 \\
A2 & 0.060 & 0.036 & 0.044 & 0.045 & 0.058 \\
A3 & 0.047 & 0.030 & 0.056 & 0.027 & 0.040 \\
A4 & 0.047 & 0.021 & 0.056 & 0.027 & 0.024 \\
A5 & 0.041 & 0.025 & 0.056 & 0.027 & 0.019 \\
\hline
\end{tabular}

The initial decision making matrix has been normalized first, as discussed in previous section. The weighted normalized decision making matrix is presented in Table 6. According to the results of Table 7 which shows evaluation of utility degree, $\mathrm{A}_{5}>\mathrm{A}_{4}>\mathrm{A}_{3}>\mathrm{A}_{1}>\mathrm{A}_{2}$.

According to the last column of Table 7, A5 is defined as the best alternative method.

Ranking of light supply in the public safe spaces based on each index has been laid in Table 5, briefly. As observed, the alternative of light supply by the lamp of battery source has been choTable 7. Final results and ranking

\begin{tabular}{lllll}
\hline $\mathrm{P}$ & $\mathrm{R}$ & $\mathrm{Q}$ & $\mathrm{N}$ & Ranking \\
\hline 0.072 & 0.143 & 0.169 & $60.50 \%$ & 4 \\
0.080 & 0.163 & 0.165 & $53.30 \%$ & 5 \\
0.086 & 0.114 & 0.208 & $75.9 \%$ & 3 \\
0.076 & 0.098 & 0.218 & $88.20 \%$ & 2 \\
0.080 & 0.087 & 0.240 & $100 \%$ & 1 \\
$R_{\text {min }}$ & 0.087 & & & \\
\hline
\end{tabular}

sen as the best choice according to experts' ideas that represents the importance of it versus other alternatives. Choices of light supply by the light of fossil fuel, light supply by the lamp of city power source and light supply by the mirror are located in second, third and fourth positions. In this evaluation, the choice of light supply by fiber-optic is in the lowest place among other alternatives that indicates poor importance of this choice.

\section{CONCLUSIONS}

In the study, in order to assess the best kind of light in the shelters, first, affective criteria were exploited by experts and specialists. To determine the best index, SWARA method was employed that as a result of it, Function and Responding to the requirements was chosen as the best criterion. Then, in order to analyze data of the questionnaire, COPRAS technique was applied to choose the best choice among different strategies; eventually, this method represented that the choice of light supply by the lamp of battery source is the best to provide light for urban shelters. Based on these results, the alternatives of light supply by the light of fossil fuel, light supply by the lamp of city power source, light supply by the mirror and light supply by fiber optics are located in second, third, fourth and fifth positions in order. The results are valid for five alternatives and the five criteria. The other conditions and of other assumptions the results will be different. However, the method remains the same. Thus, Choosing the light supply by the lamp with battery source as the best strategy of supplying light in shelters can be related to its utilities such as this point that in ordinary conditions in which city power system is in the normal state, batteries can be charge to be used in the emergency and crisis times when infrastructures and electricity failure may be occurred in. the significant point of this method is the capability of monthly and cyclical controlling of these batteries in order to prevent it from degenerating. The other reason that this way was chosen as the best among other present alternatives is its capability of storage; because batteries can be stored in a specific place in the shelter to be utilized in the crisis duration.

\section{REFERENCES}

Aghdaie, M. H.; Hashemkhani Zolfani, S.; Zavadskas, E. K. 2012. Prioritizing constructing projects of municipalities based on AHP and COPRAS-G: a case study about footbridges in Iran, The Baltic Jour- 
nal of Road and Bridge Engineering 7(2): 145-153. http://dx.doi.org/10.3846/bjrbe.2012.20

Aghdaie, M. H.; Hashemkhani Zolfani, S.; Zavadskas, E. K. 2013a. Decision making in machine tool selection: an integrated approach with SWARA and COPRAS-G methods, Inzinerine Ekonomika - Engineering Economics 24(1): 5-17. http://dx.doi.org/10.5755/ j01.ee.24.1.2822

Aghdaie, M. H.; Hashemkhani Zolfani, S.; Zavadskas, E. K. 2013b. Market segment evaluation and selection based on application of Fuzzy AHP and COPRAS-G methods, Journal of Business Economics and Management 14(1): 213-233. http://dx.doi.org/1 $0.3846 / 16111699.2012 .721392$

Alcini, C. M.; Schiavoni, S.; Asdrubali, F. 2015. Simulation of daylighting conditions in a virtual underground city, Journal of Daylighting 2: 1-11. http://dx.doi.org/10.15627/jd.2015.1

Bitarafan, M.; Hashemkhani Zolfani, S.; Arefi, S. L.; Zavadskas, E. K. 2012. Evaluating the construction methods of cold-formed steel structures in reconstructing the areas damaged in natural crises, using the methods of AHP and COPRAS-G, Archives of Civil and Mechanical Engineering 12(3): 360-367. http://dx.doi.org/10.1016/j.acme.2012.06.015

Bitarafan, M.; Hosseini, S. B.; Abazarlou, S.; Mahmoudzadeh, A. 2013. Selecting the optimal composition of architectural forms from the perspective of civil defense using AHP and IHWP methods, Architectural Engineering and Design Management 11(2): 137-148. http://dx.doi.org/10.1080/17452007.2 013.802982

Carmody, J.; Sterling, R. L. 1993. Underground space design. John Wiley and Sons Ltd.

Durmisevic, S. 1999. The future of the underground space, Cities 16(4): 233-245. http://dx.doi.org/10.1016/ S0264-2751(99)00022-0

FEMA 361. 2000. Design and construction guidance for community shelters. Federal Emergency Management Agency (FEMA), July 2000, 222 p.

Fouladgar, M. M.; Yazdani Chamzini, A.; Lashgari, A.; Zavadskas, E. K.; Turskis, Z. 2012. Maintenance strategy selection using AHP and COPRAS under fuzzy environment, International Journal of Strategic Property Management 16(1): 85-104. http:// dx.doi.org/10.3846/1648715X.2012.666657

Ginevičius, R. 2011. A new determining method for the criteria weights in multi criteria evaluation, International Journal of Information Technology \& Decision Making 10(6): 1067-1095. http://dx.doi.org/10.1142/ S0219622011004713

Ghorabaee, M. K.; Amiri, M.; Sadaghiani, J. S.; Goodarzi, G. H. 2014. Multiple criteria group decision-making for supplier selection based on COPRAS method with interval type-2 fuzzy sets, International Journal of Advanced Manufacturing Technology 75(5-8): 11151130. http://dx.doi.org/10.1007/s00170-014-6142-7

Hashemkhani Zolfani, S.; Chen, I. S.; Rezaeiniya, N.; Tamošaitienè, J. 2012a. A hybrid MCDM model encompassing AHP and COPRAS-G method for the selection of company supplier: a case in Iran, Technological and Economic Development of Economy 18(3):
529-543. http://dx.doi.org/10.3846/20294913.2012.7 09472

Hashemkhani Zolfani, S.; Rezaeiniya, N.; Aghdaie, M. H.; Zavadskas, E. K. 2012b. Quality control manager selection based on AHP-COPRAS-G methods: a case in Iran, Economska IstraživanjaEconomic Research 25(1): 88-104.

Hashemkhani Zolfani, S.; Zavadskas, E. K.; Turskis, Z. 2013a. Design of products with both international and local perspectives based on Yin-Yang balance theory and SWARA method, Economska Istraživanja - Economic Research 26(1): 153-166.

Hashemkhani Zolfani, S.; Esfahani, M. H.; Bitarafan, M.; Zavadskas, E. K.; Lale Arefi, S. 2013b. Developing a new hybrid MCDM method for selection of the optimal alternative of mechanical longitudinal ventilation of tunnel pollutants during automobile accidents, Transport 28(1): 89-96. http://dx.doi.org/ 10.3846/16484142.2013.782567

Hashemkhani Zolfani, S.; Farrokhzad, M.; Turskis, Z. 2013c. Investigating on successful factors of online games based on explorer, E\&M: Ekonomie a Management 16(2): 161-169.

Hashemkhani Zolfani, S.; Aghdaie, M. H.; Derakhti, A.; Zavadskas, E. K.; Morshed Varzandeh, M. H. 2013d. Decision making on business issues with foresight perspective; an application of new hybrid MCDM model in shopping mall locating, Expert Systems with Applications 40(17): 7111-7121. http://dx.doi. org/10.1016/j.eswa.2013.06.040

Hashemkhani Zolfani, S.; Zavadskas, E. K. 2013. Sustainable development of rural areas' building structures based on local climate, Procedia Engineering 57: 1295-1301. http://dx.doi.org/10.1016/j.proeng.2013.04.163

Hashemkhani Zolfani, S.; Maknoon, R.; Zavadskas, E. K. 2015. Multiple Nash equilibriums and evaluation of strategies. New application of MCDM methods, Journal of Business Economics and Management 16(2): 290-306. http://dx.doi.org/10.3846/1611 1699.2014.967715

Kashi, A. A. 2009. Assessment of passive defence in tunnels of people's settlement, Master's thesis of Passive Defence. Technological University of Malek Ashtar.

Keršulienè, V.; Turskis, Z. 2011. Integrated fuzzy multiple criteria decision making model for architect selection, Technological and Economic Development of Economy 17(4): 645-666. http://dx.doi.org/10.3846/20 294913.2011.635718

Keršulienè, V.; Zavadskas, E. K.; Turskis, Z. 2010. Selection of rational dispute resolution method by applying new step-wise weight assessment ratio analysis (SWARA), Journal of Business Economics and Management 11(2): 243-258. http://dx.doi.org/10.3846/20 294913.2011.635718

Lale Arefi, S. H.; Bitarafan, M. 2013. Assessment of various methods of rehabilitation in underground structures against threats caused by explosion through AHP (analytic hierarchy process) method, Tunneling and Underground Spaces Engineering 2(1): 65-74. (In Persian) 
Narjabadi Fam, N.; Hassan Beig, M. H.; Rabani, A. 2011. Designing of solar light system by fiber optics through DIALUX software and evaluation of its environmental advantages, in $2^{\text {nd }}$ Conference on Environmental Planning and Management, Tehran, Iran.

Pezeshkpour, M. A.; Motamedi, E. 2005. Geometric optics. Tehran: Fatemi.

Pitchipoo, P.; Vincent, D. S.; Rajini, N.; Rajakarunakaran, S. 2014. COPRAS decision model to optimize blind spot in heavy vehicles: a comparative perspective, Procedia Engineering 97: 1049-1059. http://dx.doi.org/10.1016/j.proeng.2014.12.383

Rezaeiniya, N.; Hashemkhani Zolfani, S.; Zavadskas, E. K. 2012. Greenhouse locating based on ANPCOPRAS-G methods - an empirical study based on Iran, International Journal of Strategic Property Management 16(2): 188-200. http://dx.doi.org/10.38 46/1648715X.2012.686459

Saaty, L. T. 1980. The analytic hierarchy process. New York: McGraw Hill Company.

Saaty, L. T.; Vargas, L. G. 2001. Models, methods, concepts \& applications of the analytical hierarchy process. Boston: Kluwer Academic Publishers.

Shannon, C. E. 1948. The mathematical theory of communication, Bell System Technical Journal 27: 379-423. http://dx.doi.org/10.1002/j.1538-7305.1948. tb01338.x

Shin, J. Y.; Yun, G. Y.; Kim, J. T. 2011. Daylighting and energy performance prediction of a light pipe used in underground parking lots, in $5^{\text {th }}$ International Symposium on Sustainable Healthy Buildings, 10 February 2011, Seoul, Korea, 277-282.

Sušinskas, S.; Zavadskas, E. K.; Turskis, Z. 2011. Multiple criteria assessment of pile columns alternatives, The Baltic Journal of Road and Bridge Engineering 6(3): 77-83. http://dx.doi.org/10.3846/bjrbe.2011.19
Stanujkic, D.; Karabasevic, D.; Zavadskas, E. K. 2015. A framework for the selection of a packaging design based on the SWARA method, Inzinerine Ekonomika-Engineering Economics 26(2): 181-187.

Vafaeipour, M.; Zolfani, S. H.; Varzandeh, M. H. M.; Derakhti, A.; Eshkalag, M. K. 2014. Assessment of regions priority for implementation of solar projects in Iran: new application of a hybrid multi-criteria decision making approach, Energy Conversion and Management 86: 653-663. http://dx.doi.org/10.1016/j. enconman.2014.05.083

Vaezizadeh, F.; Kazemzade, M. 2013. Investigating different strategies for light and ventilation provision in vernacular underground architecture and their integration with underground museums architecture - a case study in Iran, International Journal on Technical and Physical Problems of Engineering 5(17): 63-71.

Xiaobin, Y.; Zhilong, C.; Lichang, S. 2014. Analysis on the influences of underground space development on urban residential environment, Journal of Chemical and Pharmaceutical Research 6(7): 1296-1300.

Zavadskas, E. K.; Kaklauskas, A. 1996. Determination of an efficient contractor by using the new method of multi criteria assessment, in Langford, D. A.; Retik, A. (Eds.) International symposium for the organization and management of construction. Shaping theory and practice, Vol. 2: Managing the construction project and managing risk. CIB W 65. London: E and FN SPON, 94-104.

Ziabakhsh, N.; Mokhtabad-Amrei, S. M. 2010. Making the natural light in architectural spaces meaningful in two films: winter light of Bergman and Pari Mehrjui, Periodical of Honarhay e Ziba - Honarhay e Namayeshi va Mousighi 42: 59-70. 